\title{
Characterization of partitioning behaviors of immunoglobulin $G$ in polymer-salt aqueous two-phase systems
}

\begin{abstract}
The partitioning behavior of immunoglobulin $\mathrm{G}$ ( $\mathrm{IgG})$ in the aqueous two-phase system (ATPS) composed of poly(ethylene glycol) (PEG) and phosphate was studied. The parameters of ATPS exhibiting the pronounced effects on the partitioning behavior of $\mathrm{IgG}$ include phase composition, PEG molecular weight, and the addition of sodium chloride $(\mathrm{NaCl})$. The accumulation of IgG at the interface of the ATPS increased drastically as the tieline length (TLL) was increased. This trend was correlated with a linear relationship relating the natural logarithm of interfacial partition coefficient (ln G) to the difference of PEG concentration between the top phase and the bottom phase $(\Delta[\mathrm{PEG}])$, and a good fit was obtained. An attempt was made to correlate the natural logarithm of partition coefficient (ln $\mathrm{K})$ to the presence of $\mathrm{NaCl}$ with the proposed linear relationship, $\ln \mathrm{K}=\alpha$ " $\ln \left[\mathrm{Cl}^{-}\right]+\beta^{\prime \prime}$. The proposed relationship, which serves as a better description of the underlying mechanics of the protein partitioning behavior in the polymer-salt ATPS, provides a good fit $\left(\mathrm{r}^{2}>0.95\right)$ for the data of IgG partitioning. An optimum recovery of $99.97 \%$ was achieved in an ATPS (pH 7.5) composed of $14.0 \%(\mathrm{w} / \mathrm{w})$ PEG 1450, $12.5 \%(\mathrm{w} / \mathrm{w})$ phosphate and $5.0 \%(\mathrm{w} / \mathrm{w}) \mathrm{NaCl}$.
\end{abstract}

Keyword: Aqueous two-phase system; Bioseparation; Immunoglobulin G; Protein recovery; Purification; Statistical mechanics 